\title{
EL SÍNDROME DE OUROBOROS: CINE Y MONSTRUOS DEL ECUADOR
}

\author{
Juan Pablo Castro Rodas*
}

\section{Exceso y carencia}

Omar Calabrese en uno de sus trabajos sobre cine realizaba una aproximación a lo que consideraba un mundo desplegado a partir de lo deforme, en medio de un conjunto de mediaciones que configuran esta Era superpoblada de signos, hiperconectada, y profusa en sentidos ${ }^{1}$. Partía de establecer que la humanidad, desde siempre, había elaborado una serie de seres que, de alguna manera, presumían una suerte de exculpación de los propios miedos o pecados humanos. Así aparecen gigantes, centauros, cíclopes, enanos, gnomos, pigmeos; gasterópodos, sciópodos, blénidos. Casi todos se cimentaban en la relación fealdad-maldaddeformidad-disforia. Es decir, que un personaje al que se lo definiera como feo, necesariamente debía ser, además, malo, deforme y, por lo tanto, disfórico. Y lo opuesto: el ser bello, era desde luego, bueno, conforme y eufórico. Calabrese elabora su texto sobre la base de lo que denomina el "exceso", o sea, aquello que está más allá del límite, y se acerca al estudio de películas como Alien, Terminator, Star Trek, Hulk, La Mosca, entre otras.

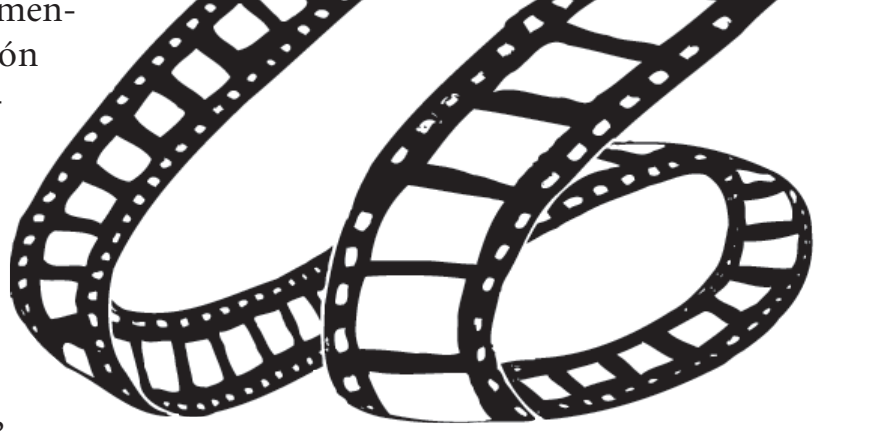

* Docente de la Carrera de Comunicación Social de la Universidad Politécnica Salesiana-Ecuador.

1 Omar Calabrese. La era neobarroca. Madrid, Cátedra, 1996. 
También Zizek asume la categoría de exceso a la que opone la de carencia. De tal manera que aquello que está más allá del centro, el exceso, se encuentra con la carencia, que está al margen. Así exceso y carencia son dos elementos de la misma unidad significativa ${ }^{2}$. En esta disputa el exceso representa lo que sobra, lo que está demás, ese otro desplazado del núcleo esencial del Orden social ${ }^{3}$. Y la carencia lo que falta, lo que se desea, no sólo desde el impulso de la sobrevivencia, sino, y talvez por sobre todo, lo que se quiere, lo que el discurso del consumo nos impulsa a obtener.

En muchas de las películas de nuestro reciente cine ecuatoriano ese presupuesto de lo monstruoso, lo excesivo, lo carente, también están presentes. En las películas, casi siempre, es posible encontrar una relación entre el centro y los márgenes, entre lo que sobra y lo que falta, como una constante narrativa que se junta entre cada película, creando una suerte de anillos encadenados. Así, cada película resulta un antes y des- pués de las que continúan, en un todo centrífugo.

¿Y esta presencia, una y otra vez, no constituye un encierro, una condena a una suma de supuestos icónicos, de referencias visuales que nos impulsan a creer que así somos, que nuestras narrativas, por tanto nuestras sensibilidades y conciencias colectivas, son únicamente ésas, en un eterno ir y venir, sin salir más allá, en un encuentro con el Síndrome de Ouroboros?

¿Es el cine una posibilidad de acercarse a lo que somos, es un reflejo, un modelo de representación, un espejo; o es una distorsión, un espejismo, una alucinación y, por eso mismo, una narrativa que se incluye en los discursos políticamente correctos, o simplemente la suma de indicios, de huellas, de meras proyecciones en una inmensa caverna de cemento?

Lenin decretó que uno de los mecanismos de legitimación de su proyecto político estaba en el cine. De ese período quedan algunas piezas maravillosas: El acorazado Po-

2 Slavoj Zizek. Lacrimane Rerun. Ensayos sobre cine moderno y ciberespacio. Debate, Barcelona, 2006. Zizek desarrolla esta dualidad para establecer algunas reflexiones sobre cine y ciberespacio. Y, en ese ejercicio, establece la relación entre exceso y carencia en torno a la producción y la pobreza.Y retoma a Hegel en lo correlativo al "exceso de la opulencia".

3 Recuerdo en el año 2005 cuando fui invitado a un encuentro de jóvenes escritores a Bogotá. Ahí, mientras la ciudad se veía desde la seguridad del auto, la encargada de asuntos culturales de la Embajada de Ecuador en Colombia hablaba de los marginales, los mendigos, los menesterosos con la terrible denominación de "los descartables". 
temkim, por ejemplo. En esta película el ideal de un pueblo que se subleva ante la autoridad y la necesidad de constituirse como sujetos de su propia historia, se presentan como directrices fundamentales. El personaje colectivo, la suma de rostros y puños que se levantan, y la victoria final. ¿Era el pueblo ruso el sujeto real de estos acontecimientos recreados desde el ojo del cineasta? Quizá sí. Y quizá sólo una invención del naciente imperio soviético. Pero, en los dos casos, el resultado de una mirada a la realidad ${ }^{4}$, sea para reproducirla, sea para inventarla. El drama de la mujer que mira cómo se desliza el cochecito del bebé, en la célebre Escalera de Odessa, la madre que lleva en sus brazos a su hijo moribundo mientras se enfrenta a los cosacos, son secuencias emblemáticas, imbuidas del expresionismo político necesario, pero, y talvez por eso mismo, rebosantes de naturaleza humana. En su construcción se bus- caba establecer representaciones cercanas, íntimas con los momentos de la revolución bolchevique. Si bien Eisenstein respondía a las directrices del Politburó, era parte de la historia de la revolución o de sus imaginarios la que, más allá de las cargas ideológicas, se mostraba en la pantalla.

Ese doctor Caligari y el sonámbulo, supuesto asesino en serie, que saldrían de ese universo cubista y sombrío de El gabinete del Dr. Caligari, resultan una explicación visual de un momento de terrible desconcierto de la sociedad alemana de la primera posguerra del siglo XX. La aparente incapacidad de organizar ese mundo y la crisis de la razón se evidencian en esta película de Wiene, y a través de los escenarios distorsionados accedemos a la mirada metaforizada de esa realidad. A un acercamiento descarnado con lo que supone la fundamental sustancia de la especia humana: el absurdo supremo, la irracionalidad paradoja que surge de la razón, o la locura ${ }^{5}$.

4 Mirar a la realidad es, en sí misma, una aparente imposibilidad. Sobre todo si se pretende que esta mirada esté revestida de un estado puro de conciliación. Como si entre el ojo y el mundo no hubiese de por medio un territorio intangible de signos, una opacidad que provenga del propio ojo, o una realidad que siendo materia y sustancia, sea, sobre todo, una versión hiperreal que hemos aceptado desde la convención social. Aún más, esa realidad siempre puede ser el sueño, la proyección, el deseo. Sin embargo, en el acto de creación, el artista político -aquel que está determinado, además, por las determinaciones de una supra institucionalidad- pretende que sus juegos subjetivos, que sus propias opacidades se subordinen a un ethos histórico.

5 Son interesantes, en ese sentido, los aportes que se pueden sustraer de los textos El mito de Sísifo de Albert Camus, Elogio a la locura de Erasmo de Rótterdam y por supuesto todas las reflexiones de Michael Foucault. 
La lánguida figura de Antonio, que busca su bicicleta robada, y el rostro aterrorizado de su hijo Bruno cuando su padre es atrapado al intentar "recuperar" otra bicicleta, parecen acercarse a esa sensación de desamparo y abandono que el pueblo italiano vivía luego de la Segunda Guerra Mundial. Y ese mismo pueblo que se junta con Antonio, a la salida de un partido de fútbol, ¿no resulta, acaso, la expresión de una Italia que camina hacia adelante, que se junta en un todo anónimo, nostálgico, susurrante, al tiempo que le llega? Quizás este nivel de pertenencia explique por qué muchos espectadores abdicaban esta película. El Neorrealismo, que Vittorio De Sica exacerba en este film, aproximaba con violencia a una materialidad que muchos italianos querían empezar a olvidar. Y aunque la cinematografía italiana ha aportado con los spaghetti-western, las comedias eróticas de los años setenta, y los espectáculos históricos peplum, es el neorrealismo el que ha dejado una impronta discursiva que junta lo visual, con lo político y con lo estético.
¿No es el cine de los Estados Unidos, desde Porter, Griffith (sobre todo en Nacimiento de una nación), y luego, cuando ya nació Hollywood, un espacio abierto a los imaginarios que pueblan la psiquis de los gringos? Una lista al azar 6 podría demostrarnos cómo su proyecto de nación se encuentra estrechamente vinculado con sus principios imperiales.

¿Es imposible encontrarse con la burguesía decadente, retratada desde los ojos melancólicos de un Charlot humanizado, parodia del dandy londinense, en medio de las callejuelas de la ciudad? ¿O en las expresiones terribles y maravillosas en $\mathrm{El}$ dictador, Luces de la Ciudad o La fiebre del oro?

Hasta en el mismo Perro andaluz -primer intento surrealista de cine, hoy menos surrealista que antes- es posible encontrar las significaciones de la España degenerada, que habitaba en los ojos alucinados de Buñuel y Dalí. Y aunque su discurso es quizás el más subjetivo de todos, no dejan de entreverse sustancias y sentidos de la historia que emergen entre las líneas poéticas ${ }^{7}$.

Desde Ciudadano Kane, hasta Mars Ataca, pasando por la saga de Las Guerras de las Galaxias, James Bond, y todas aquellas que se acercan a los conflictos bélicos (Viet Nam, II Guerra Mundial, Irak, etc.)

7 Toda película es el resultado de una idea, como decía Jean Mitry, y, por lo tanto, de un conjunto de referencias simbólicas que están detrás de esa idea. La cámara constituye el ojo del realizador, el encuentro de sus sentidos y sus subjetividades, pero, por efectos de las telarañas culturales, del propio marco de la historia. 
En muchas películas de la historia del cine mundial es posible ese encuentro con los colectivos humanos que están detrás. Muchos y muchas de quienes han asistido a las salas oscuras, desde los inmigrantes que iban a los nickelodions a buscar refugio y paz ${ }^{8}$, hasta los frenéticos amantes debieron sentir que sus vidas estaban "retratadas" en la piel blanca de la proyección ${ }^{9}$. Este entrelazamiento lacaniano supone, quizás, la base estructural-simbólica que propicia que el cine sea cine. $\mathrm{O}$ lo que es casi lo mismo, en el cine es posible el derroche de la escopofilia, es decir, de esa naturaleza humana que no se resiste a mirar a los otros, o al Otro, ese orden social, como concibiera Zizek $^{10}$. De tal suerte que el sujeto frente a frente con el Otro-representación icónica se encuentra con su mismisidad $y$, sin embargo, con lo ajeno, lo que está más allá. En ese ejercicio de reconocimiento, el sujeto da rienda suelta a su jouissance. Es decir, al gozo, a la plenitud -fruición lo llama Eco- que posibilita la creación de un territorio simbólico en el que el sujeto-observador se enfrenta lascivamente con ese sujeto-objeto, con ese otro, que es él mismo y todos los humanos, pero que, por los efectos de su relación cronotópica, sigue siendo único y singular.

¿Pero es así de cierto: el espectador se siente proyectado-identificado con los sujetos-objetos y sus situaciones que se proyectan en el film, tal como señala Edgar Morin? ¿De ser así, hasta qué punto esa representación es real, y no el resultado de los propios imaginarios que designan la realidad, que la codifican, que le dan otros sentidos, quizás alejados de aquellos que construyen la vida diaria? ¿O solamente se trata de un simulacro, de un ejercicio de acepta-

Los migrantes irlandeses, escoceses, italianos, y demás, se les debe el impulso a la naciente industria del cine, ya que llenaban las salas para evadir la realidad política, cultural y simbólica y sobre todo lingüística que les apretaba. Luego el nacimiento de la industria era el resultado obvio de una sociedad industrial, cuya base está en la economía de mercado, y en su producción de bienes culturales. En Europa, y muchos años después, el movimiento del comercio -y las búsquedas estético-expresivas- consolidaron la dinámica cinematográfica.

9 Jean Mitry, señala como la sala de cine constituía en los inicios del cine, además, ese oscuro espacio de lo prohibido, aquello que se oculta en la oscuridad y que supone, digo yo, el acceso a un mundo del pecado, del mal. El cine, o ir al cine, todavía en ciertas prácticas humanas resulta el paso preliminar al acto sexual, como en la película cubana Fresa y chocolate, en cuya primera secuencia se habla del cine precisamente como eso: un camino inicial que deberá terminar, casi siempre, en el acoplamiento de los amantes. Ir al cine, se ve en innumerables películas del cine hollywodense, implica un acuerdo de mutua seducción. De ahí que el cine esté todavía poblado de sentidos eróticos.

10 Zizek, Slavoj, Op. Cit. 
ción de que ese Otro es mera iconización, virtualización, iconosfera?

En el transcurso de los tiempos las nociones sobre belleza y estética se transforman, supeditadas a los mandamientos del canon. De no ser así, sería imposible entender cómo las regordetas de Rubens, que se muestran así voluptuosas en Rapto de las hijas de Leucipo, hoy supondrían el escarnio, más cercanas al sobrepeso de Súper Size me que a los elogios de los espectadores.

Desde luego esa noción, que acepta o rechaza una supuesta verdad estética, no radica exclusivamente en el canon. Porque ahora las miradas que legitiman estos principios no están encerradas en la Academia. Son los Medios de Comunicación o sus discursos multidiscursivos los que operan a la hora de crear simbologías o legitimar sentidos. Entonces "lo bello" y "lo feo" están encerrados en el territorio de lo virtual. Y por lo tanto su centro, su sentido de realidad se traslada a las simulaciones. A construcciones periféricas pero, hoy más que nunca, aceptadas como matrices de los discursos. Así, los encuadres y las secuencias, el montaje y todo el apa- rataje discursivo de la televisión y del cine implantan un nuevo mundo. Estamos hoy al borde del redescubrimiento de la naturaleza humana, aquella que habitaba en los nuevos discursos y los modelos narrativos. Este viaje hacia el centro cibernético de la civilización está en marcha, y los vientos informáticos, cibernéticos, nanotécnicos nos desplazan hacia un nuevo mundo que quizás está alrededor y que, por encontrarnos dentro, no lo podemos ver. Vivimos una fascinación virtual. Un territorio de simbologías y representaciones icónicas que se impulsan mutuamente, como si se tratase de una capa de espejos. $\mathrm{O}$, en términos más borgianos, a un laberinto que se desplaza ad infinitud dentro de un movimiento ondulatorio, pero capaz de caber en un corpúsculo. Tal como Anaximandro pensara en torno a las partículas elementales de la naturaleza física. Ese territorio, fascinante y virtual, que impide mirarnos de frente, que nos atrapa y nos succiona ${ }^{11}$. A ese estado de delirio denominamos El síndrome de Ouroboros.

Dice Montalbán: "Ouroboros (...) traduce el mito de la serpiente que se muerde la cola y que encerra-

11 Espacio virtual de condena humana que está presente en la saga de Matrix. ¿O no supone precisamente esto: un inmenso, pero falso, mundo de pulsaciones binarias que, superpuestas en un orden matemático y fatídico, llevan al encierro de la especie humana? 
da sobre sí misma simboliza un ciclo de la evolución. Da la idea de movimiento, continuidad, autofecundación, perpetuo retorno. O también el encuentro fatal de los contrarios, el Bien y el Mal..."12.

Pero también constituye el encierro, el cuerpo atrapado sobre sí mismo, la vida y la muerte conectadas en un abrazo eterno, indiferenciado, en donde la luz y oscuridad son una misma entidad, y, por lo tanto, la ceguera, que es la incapacidad de mirarnos y de reconocernos.

Un síndrome que nace de una nación irresuelta, de un proyecto histórico que nunca se encontró a sí mismo, y, quizás hoy más que nunca, de una dinámica mediática que se inscribe en la voracidad significativa de los discursos.

Así, lo que los amantes de la Escuela de Frankfurt llaman Industria Cultural, y los medios y sus discursos se convierten en los creadores de un nuevo territorio de sentidos. De alguna manera la idea de Oikos, en cuanto morada humana, está hoy cimentada sobre la base de los pilares virtuales que nacen de la televisión, el cine, internet ${ }^{13}$, y de las narrativas que emergen de estos.

La noción de belleza, creada e impulsada a través de estos discursos, aparece así unívoca y diferenciadora. Todo aquello que se sale de esa forma aceptada resulta deforme, horrible y monstruoso. Ya no son los gigantes o los cíclopes, los monstruos que pueblan el imaginario de occidente, son los "otros" los que están fuera, al margen, en los límites de una razón y su estética. En ese Otro, nuevo orden simbólico y social, los sujetos que no sintonizan con los presupuestos de una nueva, concreta y aceptada, son marginados.

El cine permite el reconocimiento de los sujetos, o su diferenciación. En esa dinámica se incorporan las nociones de belleza o fealdad, a partir de los propios imaginarios del realizador, y sobre todo, se articulan desde la cultura. De ahí que esos otros monstruosos son, en última instancia, la reproducción de los estereotipos que se encuentran insertados en la dinámica simbólica de los

12 Manuel Montalbán Vásquez. El premio. Planeta, Madrid, 2004:240.

13 Aunque en Ecuador los datos oficiales hablan de una cobertura que no alcanza ni el 5\% de la población, el discurso que se desplaza desde la Internet tiene la posibilidad de ir más allá de las propias fronteras tecnológicas, de sus soportes físicos, hasta constituir una suerte de sensación, de atmósfera que está por sobre todo. En Next, Anagrama, Madrid, 2002, Alejandro Barico considera que la globalización y la Internet parecerían ser más que nada un espejismo, un imaginario, que no necesariamente tiene la cobertura que se le otorga. Pero por sobre los datos reales está esa inmensa cobertura simbólica que parece atravesar estos tiempos. 
individuos que conforman una nación, o un territorio simbólico.

Así las cosas, en las películas ecuatorianas más recientes ${ }^{14}$, algunos de los personajes aparecen como esos "otros", configurados desde lo marginal y lo deforme. ¿Pero son estas representaciones de lo que somos los ecuatorianos, qué nivel de cercanía e identificación es posible encontrar entre los personajes y los sujetos reales? ¿En el cine somos lo que se muestra, lo que intuimos como realidad, o el resultado de lo que creemos que debemos ser, lo que nos han enunciado como tal? ¿No será que en ese acto de mimesis, de reproducción de lo que los discursos nos dicen que somos, estamos aceptando una versión de las cosas, una forma de significarnos, una manera, reducida y empobrecida, de escribir nuestras narrativas? 15 .

¿No será que en esa construcción de otros lenguajes, la telaraña de sentires y pulsaciones, la palabra imposible de asir, la palabreja llamada identidad $^{16}$, termina por huir, por evadirse, $\mathrm{o}$, en el peor de los casos travestirse? ${ }^{17}$ ¿Esta forma de figurarnos, no supondrá precisamente un exceso en sí misma, una proliferación de sentidos visuales que están en medio de una glotonería, de una obesidad

14 Mientras reviso este ensayo en Ecuador se han estrenado Tan lejos (2006) y Esas no son penas (2007). La primera un acercamiento, desde el humor leve, a parte de los imaginarios en torno a la idea de "lo ecuatoriano", quizás sea mejor decir de "lo serrano", y de su clase media-media alta. Este film se aleja del ideal de lo monstruoso en cuanto deformidad. No hay sujetos marginales - presentes en los otros filmes muy en tono con lo que se llama en Realismo Sucio- ni escenarios grotescos. El tono ligero de su historia, y las premisas de un lenguaje económico hacen de este film un punto de giro en nuestra reciente historia cinematográfica. La segunda, un melodrama en torno a algunas mujeres de la clase media alta quiteña venida a menos. El tono sentimental, una suerte de encierro lánguido y triste, y el desprendimiento de una dramaturgia convencional, así como la presencia de un Quito brumoso y desolador constituyen algunos de sus logros. La falta de una estructura dramaturgia sólida, así como las graves deficiencias en su ritmo son algunos de los elementos que van en desmedro del film. Tampoco en este film se recurren a personajes monstruosos. ¿Estamos ante un nuevo momento del cine nacional, un acercamiento a otras emociones, a otras miradas y sensibilidades; son estos dos films el punto de giro hacia un nuevo modo de mirarnos, a un manera distante de construir nuestras narrativas?

15 Iván Carvajal, en su ensayo “Volver a tener Patria”, en La cuadratura del tiempo, Orogenia, Quito, 2006, desarrolla una sugestiva visión en torno a la relación entre país y textualidad en el que afirma que un país se construye a partir de sus narrativas.

16 El debate sobre la identidad ha supuesto siempre un acercamiento a lo evanescente. A aquello que se dificulta de encontrar porque está en nosotros mismos, y por ello, imposible de mirar. En el caso de México, señalado por algunos despistados como el centro de una identidad sólida, el propio Octavio Paz en El laberinto de la soledad trata de explicarse, desde la distancia que le permitía su paso por los Estados Unidos, lo que supone lo mexicano.

17 Tal como se ha visto en las elecciones presidenciales de 2006, en donde la candidata del PSC, constituía el cuerpo y la cara de otro ser, ya viejo y cansado león, en un claro ejemplo de travestimiento político. 
imposible ya de parar? ${ }^{18}$ ¿Y este exceso, no conllevará, necesaria y terriblemente, al renacimiento eterno de monstruos, en un sinfín de emanaciones escatológicas y marginales?

En el ejercicio de acercarnos a varios de los personajes de nuestra cinematografía reciente, pretendemos que estás preguntas se abran en sus múltiples sentidos y que sea el lector, en primera y última instancia, quien se encargue de asirlas.

\section{La Tigra}

La Tigra se construye como un personaje que está en permanente disputa con ese otro. Contrariamente a su versión literaria ${ }^{19}$, a esta Tigra no le importa la aceptación de sus hermanas. Cínica y gozosa se regodea en su poder.

En una de las secuencias se enfrenta con el Ternerote. Ha descubierto, a través de una curación mágica, que éste es el autor intelectual de las muertes de su padre y madre. Mientras los ojos de la Tigra y el Ternerote se cruzan, sus respectivos gallos ensangrientan la gallera. Vencedora la Tigra, llega la elipsis.
En la siguiente secuencia dos viejos descubren al Ternerote colgado en un árbol. Hasta este punto el decurrir del drama permite que la venganza aparezca justificada. Es posible establecer una solidaridad con la Tigra. Pero cuando Juliana, amante enamorada del Ternerote, le pregunta sobre su muerte, la Tigra, en vez de explicar los motivos que le llevaron a matarlo, prefiere ironizar con el perico como su sustituto.

Aquí la Tigra se deforma. Su actitud le lleva con violencia, a los márgenes de la condición humana. El supuesto valor se convierte en contravalor. El ideal de una belleza natural -esbozada en su cuerpo sobre un árbol con el destello de agua a sus pies- se quiebra. Es más bien el aparecimiento de la fea, la heroína mala. En tal virtud, el asesinato cobarde de Clemente Suárez (inconcebible en el mundo creado por José de la Cuadra, ya que el núcleo familiar suponía la base del universo de las Miranda. Por ello, jamás las hermanas de la Tigra habrían podido mirar cómo asesinan a su hermana) termina por sentenciar al personaje. Se ha hecho un acto de justicia. La monstruosa ha muerto.

18 Nada comparada con La gran comilona de Marco Ferrero, en donde comida, sexo y muerte se superponen en función de resemantizar, hasta los límites, la noción de vida y placer.

19 Para mayores referencias sobre la adaptación cinematográfica del texto de José de la Cuadra, remítase a Juan Pablo Castro “Las dos tigras", Revista Kipus, No. 16, Universidad Andina, Quito, 2003. 
Así, parece ratificarse el imaginario de la malvada, pero no una femme fatal: La mujer fatal, que se sabe que es tal, que no finge, presente en innumerables películas del cine noir. No, la Tigra, no se acerca a la crueldad de la maldad, al universo poético del mal ${ }^{20}$. No puede desplegarse en esa transparencia del mal, de Baudrillard. Es sólo un ser disfórico, construye su tumba desde el inicio. Cada acto que da le lleva a justificar su propia condición. La mala se cree invulnerable. La posibilidad de "perder" le resulta impensable. De ahí que sus actos le confieran cierto grado de poder. Un poder omnímodo, pero falso. Una simulación. Un espejismo. Entonces, el acto carnal es eso, una simulación, una acción de fingimiento que se expresa en el movimiento inaudito de un techo ${ }^{21}$.

Si, como dice Morin, el espectador establece un grado de proyección-identificación con la película, cuyos vínculos estarían explicados desde las voluntades subconscientes, entonces siempre el malo, la mala, resultan atractivos. Su capacidad de seducción podría radicar en esos afa- nes perversos y oscuros tan humanos. Si, además, esos malos, esas malas, están configurados desde la belleza paradigmática, epocal, entonces ese vínculo se exterioriza, se vuelve apetecible. Se convierte en el territorio de la ilusión, del deseo.

El malo, la mala ya no es un monstruo ya que, como dijimos, esta cualidad radica en la suma de lo feo, lo malo, lo deforme y lo disfórico. En el caso de la Tigra, el personaje cinematográfico, parece sumar casi todos los niveles de condena. Es excesivamente mala, fuera de toda explicación. No hay certezas que la rediman. No hay centro simbólico. Su ser se aleja hacia los márgenes, hacia el territorio del exceso. Disfórico. Su contextura emocional la hace repulsiva. Le destruye sus cualidades humanas, la aleja del mito. Sólo la belleza -todavía próxima al monte, la mirada perdida y mezclada con la espesura de la secuencia final-, le confiere un grado mínimo de euforia. Pero ese minuto final, artificial y evanescente, es un fingimiento más, una acción ideológica que está más allá de lo inteligible, es pues, un exce-

20 Ese Mal que se encuentra espléndido y total en los textos de George Bataille, o en las designaciones del Teatro de la crueldad de Antonin Artaud.

21 Tal como lo realiza el más simplón y ordinario cine de Hollywood. Entiéndase dos amantes, dentro de un carro, en actos copulatorios. La cámara los muestra desde afuera. El auto se sube y baja, los amortiguadores suenan, la mujer gime. 
so. La noción de monstruosidad termina por ratificarse. Destruido el mito, no queda nada.

Sólo el estereotipo, que es casi nada. Una referencia al mundo de lo salvaje, lo bárbaro. La Tigra, no recupera el valor político y simbólico que está presente en el contexto de su situación personal. Ella es más que una reproducción de una maldad casi gratuita. Es, más que nada, el encuentro con la posibilidad de cuestionar y destruir el patriarcado, o como diría Bordieu, la dominación masculina. Porque ella, y el fundo de Las Miranda, mantiene una lógica de supervivencia que se basa precisamente en eso: un modelo de gestión femenino. En su cuerpo de ideas el simbólico masculino debería estar ligado a la muerte de su padre, y a la asunción de un dominio que, siendo total, no retoma las bases de lo masculino. La Tigra -cercana a la naturaleza salvaje del monte- no es un hombre. Ella se resignifica. Pero no se traviste. Es decir, siendo ella no debería incorporar un estatuto de lo masculino ${ }^{22}$.
La Tigra así: mujer-masculina, se convierte en la bárbara, dentro de su propio territorio. Lejos de constituir el centro, la referencia para su colectivo, se desplaza a los límites simbólicos. Así, su sociedad se desmorona. Y ella asume su condición de marginal. En ese acto de condena no hay nada noble. Ningún compromiso de renunciación. Ninguna señal de sacrificio o de heroísmo ${ }^{23}$. Sólo un empecinamiento febril. Tampoco le llega la locura, como estado de salvación. Un momento de enajenación iluminada y demencial que la libere, que la humanice. La Tigra, enfrentada a las balas de los policías rurales, termina por expandirse en su domino y muere.

En ese tránsito lo excesivo se manifiesta en su plenitud. Pero no esos excesos dionisíacos, tan a lo Sabina ${ }^{24}$, sino aquellos repelentes de una condición humana decadente. Son los actos de una moral retorcida, apurada a retazos, imposible de aceptarse desde las matrices de lo verosímil. Y, en cambio, aparecen las carencias. Esa suma de pequeña

22 Son referenciales, en este sentido, los caso de Tacher, en el Reino Unido, y Ginata, en el Reino de Guayaquil. Las dos, lejos de ser mujeres, asumen roles masculinos, plenipotenciarios y prepotentes.

23 Ninguna Antífona o Madre Coraje; o una Virginia Wolf de Las Horas entregada a las aguas heladas del río.

24 En uno de los regresos de sus jornadas de recuperación médica, Joaquín Sabina decía que lo que más había extrañado en su tránsito eran los excesos. Eso precisamente, los límites humanos en donde la realidad se entremezcla con la fantasía, en jornadas de delirio, y encuentros con ese Mal gozoso, con la ruptura del orden de la moral, una moral tardocapitalista que, explicitada en la arrogancia imperial, resulta falsa cada día más. 
cosas que hacen de un personaje una unidad integral, tal como dijera Mijail Bajtin. A través del personaje se puede conocer la totalidad de una obra literaria. En su entramado dramático se concentran todas las unidades significativas del discurso. Como si el personaje se constituyese en una sinécdoque del film. Y a través de esta Tigra la película no alcanza esos niveles de significación. Su presencia en el corpus fílmico se desvanece. Falta ese algo que la vuelva personaje redondo, curvilíneo, humano.

\section{3. Ángel}

La primera secuencia de Ratas... nos muestra una persecución, un mundo delirante y violento, un cementerio que supone el escenario del presagio. Ángel corre; es un sujeto perseguido, y por ello está en permanente enfrentamiento. El que huye está siempre adelante, rechaza lo que le está permitido. Ángel es un ex convicto. Su vida ha estado marcada por lo marginal. Por aquellos quiebres de lo que se conoce como lo normativo. Por el exceso: drogas, sexo y violencia. En su permanente fuga se define, se acepta. Esa es su condición. El cercenamiento de uno de sus dedos meñiques supone ese antes violento, un estado anterior de confrontación, de marginalidad y de carencia. En ese Ángel se resumen los individuos de la pobreza, de aquellos olvidados, a lo Buñuel: parias condenados desde su nacimiento, en un eterno descenso a los abismos, sin posibilidad de redención. Así, les queda sólo un enfrentamiento a la muerte, que es al mismo tiempo un intento de recuperación de la vida. Ante los otros, y ese Otroorden social, son los peligrosos, los malignos.

Ángel huye, la cámara lo sigue a prudente distancia, sin comprometerse. Se esconde y arremete contra su perseguidor. Emerge, entonces el desalmado, ese avezado delincuente, que puebla el imaginario de la televisión sensacionalista. Cada vez que golpea la cabeza del otro marginal, del otro malo, contra una columna del cementerio ese Ángel se convierte en demonio. Furioso, cruel, frío, como la muerte que ronda la película.

Cuando Ángel va a Quito, busca el amparo de su primo Salvador. Juntos, más una incipiente pandilla, entrarán en un camino sin escapatoria. La venta de un arma supondrá el inicio del fin. La confrontación con la clase media alta quiteña, y sus hijos lumpen burgueses, permitirá establecer la idea de un centro económico y simbólico. Así, los marginales se 
acercan al ideal de bien tardocapitalista: el dinero, el progreso y la familia, para hacer lo que tienen que hacer, aquello que se debe, no como un acto de reivindicación de clase, sino como una simple tarea. Robar, matar y traicionar son elementos de un estado de aceptación natural. No hay implicaciones políticas. No hay actos simbólicos de confrontación real con el poder. Ángel: monstruo callejero.

Además, estas secuencias oscuras pero fulgurantes, mientras Ángel prepara su dosis de base, son las que fragmentan aún más su condición humana. Cada vez que el personaje se somete a este encuentro alucinado, su cuerpo se dispersa en ráfagas de luz, proyectadas desde el fuego. El uso de los primeros planos, aunque permite un acercamiento a la emoción del personaje, fragilizan su humanidad. Fragmentos del rostro, pedazos del cuerpo. Tal cual un sujeto deforme. Esta búsqueda de una estética de lo marginal -tan presente en el llamado Realismo Sucio- aleja a Ángel de una plataforma integral. No es un sujeto concreto, es una suma de pedazos humanos, es decir, un mons- truo. De esta manera se reproduce el discurso oficial en torno a los marginales: seres hechos de fragmentos de cuerpos, de partes nada más, botados en medio de un charco de sangre, o sobre la morgue, con el dedo meñique del que cuelga un número. De esta manera, la violencia, la represión social que se ejerce desde el Estado resulta necesaria. Mientras más delincuentes lleguen, más represión, más muerte, más impunidad será aceptada $^{25}$. Aquí Ratas se incorpora al discurso de crónica roja, se encadena con los noticieros, los periódicos, los filmes que hacen de la marginación su estética única.

Desde luego, la fragmentación del personaje, en cuanto forma, no constituye el único nivel que permite afirmar la deformidad del personaje. Son los otros planos, el tímico, por ejemplo, en donde el personaje reafirma su decisión de estar más allá, de repudiar al otro. Así, la huida final, con las sombras y las luces proyectadas sobre su rostro, ratifica su voluntad. Atrás quedan sus cómplices abandonados, su primo, y un cadáver debajo de la cama. Y también la abuela -deformada en una enfer-

25 Recuérdense los innumerables casos de violencia, tortura y muerte que se endilga a la Policía, o a Las Fuerza Armadas que jamás han llevado el debido proceso. Esas "últimas consecuencias" devenidas solamente en un lugar común, una frase que se repite, y que nunca supone más que un enunciado de prensa. 
medad patética- a quien Ángel demostrara algún sentimiento de ternura. Los actos de traición a los otros ratifican su condición de marginal, de amoralidad: para él no existen parámetros de lo que se debe hacer, su organización simbólica del mundo se cimenta en el aquí y ahora, sin límites.

En cuanto al plano de lo bello, Ángel resulta una especie de cliché de lo criollo. Del estereotipo del mono ladrón -camiseta del Barcelona, pelo rubio teñido-, pasamos a la dureza del ladrón avezado. Aquel que camina con la camisa ensangrentada, el pómulo destrozado, la ceja quebrada. Aquel que convive en el imaginario de un país violento. Aquel que permite legitimar la necesidad de una ciudad armada. Así, la violencia aparece como la única posibilidad de controlar la violencia. Dulce bellum inexpertis.

Es pues, Ángel, un tipo malo, feo y disfórico, siempre en los límites de lo marginal, por ello, deforme. Su presencia demuestra la supuesta crisis del orden, el cuestionamiento a la sociedad, no desde una actitud política, si no desde la práctica delincuencial. Sin embargo, el personaje resulta amable, quizás no por aquellas conexiones inefables con el Mal, ni la tradición, ni la crueldad; es más bien ese carisma de lo local, esa pre- sencia de lo folclórico, ese retrato irónico de lo que parece que somos -expresado en el uso de la jerga, el habla popular, los juegos lingüísticos- lo que le confiere este sentimiento de aceptación. Ahí radica su carácter. Ese espesor dramático, de alguna manera, lo libera. Entonces la idea del delincuente, del drogadicto, del sinvergüenza, se redefine. El tratamiento desde el humor lo salva. En un monstruo, no hay duda, pero un monstruo gracioso. Y su huida final ya no es eso. Sólo la continuación de una vida que se juega en el día a día, sin remordimientos, ni planteamientos morales. De esta manera la película se engarza con la realidad, otra vez. Del mundo concreto-hipotexto, del cual surge la historia, al mundo ficticio-hipertexto, en donde se configura como film, y luego, cuando Ángel continúa por la calle oscura, a un meta-hipotexto. Realidad-ficción-metarealidad, encadenados, en anillos superpuestos de Ouroboros.

\section{El monstruo de Babahoyo}

La película empieza con el baño de un hombre en una laguna. Este lavado inicial, ritualístico de Vinicio Cepeda, nos aproxima a la conciencia del pecado. Esa condición judeocristiana que supone el territorio de lo prohibido, de lo penado. Así, el 
personaje se entrega a la purificación, en la aceptación tácita de un antes siniestro. Del agua emerge vida, pero también la muerte.

En medio del territorio de lo pobre (categoría estética de ciertas películas ecuatorianas, en las que el trasfondo de una sociedad injusta no interesa. Piénsese en Juana de Cabrera, la campesina empobrecida desde un expresionismo delirante, o los rostros de la pobreza: feos, aletargados, desdentados, tontos y violentos de Un titán en el ring, o en la abuela encerrada y abandonada de Ratas...) todo es posible. El mito del "buen salvaje" ha desaparecido. Esos sujetos sudorosos, gritones, violentos, irracionales arremeten contra Vinicio Cepeda. (¿Hasta ese momento el personaje era inocente, o tenía la culpabilidad en la piel, en los ojos? ¿Cepeda no era acaso vecino como cualquier otro? ¿Actúan así los vecinos o ya sabían que este era el violador; presuponían por qué, cómo así?). Esos "feos" resultan los salvajes de la pobreza. Monstruos todos ellos, provistos de gasolina, gritando, con los rostros exaltados, como en un cuadro barroco del Infierno.

Luego la presencia de Cepeda, dentro de la cárcel, permite reafirmar esa condición de marginal. Lacerado, se recubre con sus propios excrementos, porque en ese acto de esca- tología puede liberarse de los otros, esos otros marginales que están en la prisión, o al menos ahuyentarlos.

Cepeda encarna una marginalidad seductora. Cada palabra está concebida desde el juego de la retórica. Los susurros, los quiebres de la voz se justifican en medio de ese trance. Este monstruo, a veces en silueta, a veces ensangrentado, se regodea en su aparente inteligencia. Y es esa sutil línea entre el bien y el mal la que permite un crecimiento del personaje.

$\mathrm{Su}$ deformidad termina por determinarse hacia el final. Resulta el perverso. Es decir, el sujeto que no actúa a partir de la violencia explícita, más bien su modus operandi se sustenta en la fascinación, en la aceptación que tiene de su víctima. Así, ésta cae como resultado de su neurosis, su nivel de frustración, y la posibilidad catártica de liberación.

Más allá de algunas consideraciones psicológicas, la presencia del monstruo de Babahoyo aparece en el film como la aceptación de una sociedad disfórica. Del conjunto de sujetos que la conforman es posible el nacimiento del perverso. Cualquiera de aquellos que conforman lo turbio de las primeras secuencias podría ser otro monstruo.

Así las cosas, la deformidad y la maldad habitan en todos. De ahí que 
el mismo periodista termine convirtiéndose en otro monstruo. Sólo que este responde a los lineamentos de un sensacionalismo, cuya escala de valores está en función de la exclusiva y el ascenso profesional. La pregunta ¿quién es el monstruo?, resulta mera retórica. En Crónicas el monstruo es el violador; no el periodista, no la televisión. En el mundo real -aquel que no se altera a partir de las necesidades de la puesta en escena-, el monstruo es la pobreza. Sin embargo, en la película es sólo decorado, escenario y paisaje ${ }^{26}$. Más bien son las premisas dramatúrgicas las que determinan una supuesta lucha entre el bien y el mal. Al final lo monstruoso se ratifica. Sólo que el violador feo, malo, deforme y disfórico se mezcla con el mundo, la vegetación lo protege, los créditos finales lo liberan.

En Crónicas se concentra la dualidad exceso-carencia, como una solo entidad significativa. El exceso se manifiesta en esa inocencia perversa de Cepeda, de la que está cubierto. El amor filial permite que la esposa bote en el río las pruebas que lo inculparían. El río nuevamente aparece como signo de liberación. La esposa, de esta manera, alimenta al monstruo, sin imaginar que su hijo, hijastro del Monstruo de Babahoyo, camina con éste por entre unos matorrales. El triángulo lacaniano se presenta con el ingrediente de la madre que, sin saberlo, entrega a su hijo a las fauces del padrastro. El círculo lascivo se cierra.

La carencia se presenta en el orden de lo moral. Ese deber ser que, en principio, deberían garantizar los hechos de los seres humanos. Así, el periodista Bonilla oculta su razón de ser en los intereses personales, y rompe su estatuto de buscador de la verdad. Verdad y falsedad, aparecen juntas. En la última secuencia con los tres periodistas en su carro y la policía detrás se cierra el universo de la película. Los tres deciden no contar al policía sobre las pruebas que podrían inculpar a Cepeda. Entonces, todo lo anterior se vuelve simulación, mero conjunto de actos que se vacían de su sentido inicial. Así, todos alimentan al monstruo.

\section{Los Papitos}

Hay al menos dos casos de padres violentos en el cine ecuatoriano reciente. Y llaman la atención porque

Es parte de una importante tendencia en el cine latinoamericano que estetiza la pobreza. De esta surgen las historias, no en un ejercicio de cuestionamiento, sino de mera circunstancia contingente. Véase así Amores perros, Pizza, birra y fazo, Tinta roja, entre las más recientes, herederas de la magnifica Los olvidados de Buñuel. 
concentran esa dualidad de excesocarencia. Los dos son pobres, por tanto, marginales. Los dos son agresivos, casi teatrales, deformes. Los dos aparecen construidos desde lo feo, lo grotesco. Son entonces, seres disfóricos, rechazados -a pensar que quieran salvárseles desde una supuesta ternura o desde la muerte-. Los dos son anónimos. Son los papitos Uno "padre" de Juan en Fuera de juego, y el otro "padre" de Salvador en Ratas...

Juan es un jovenzuelo desilusionado. Su vida se teje alrededor de la idea de emigrar. Esta sensación le separa de una supuesta búsqueda del progreso. Más bien la calle, las "malas amistades" y algo parecido al amor, le llevan a transitar por bares de mala muerte. Al fondo de la película el escenario de la historia ecuatoriana actual: paros, enfrentamientos callejeros, el delirio por el fútbol.

Cada vez que Juan regresa a la casa tiene que someterse a los enfrentamientos con su padre, mientras un hermano lelo mira el televisor (resulta al menos curiosa esta metáfora de la agonía, ya que es similar a la que aparentemente encarna la abuela en Ratas...).

Este padre alcohólico y desempleado, enfrenta a su hijo desde una brutalidad verbal. Los dos, ya que Juan también responde, asumen así esa tradición del mundo masculino, que reafirma una noción de poder a través de la fuerza. La secuencia se desarrolla mientras el televisor está prendido. El mundo de lo real se mantiene en ese cuadrante. La iluminación recuerda el cine documental. Entonces, el enfrentamiento del padre con el hijo parecería establecer un nexo próximo con lo referencial. La verosimilitud se quiebra. El padre, sólo grita, mueve los brazos. La violencia última, en cuanto acto de agresión física, no llega.

Sin embargo, ante la retina se ha construido como el padre déspota, violento, cuya actitud le deforma, lo embrutece, lo afea. Ni siquiera las secuencias en que se fractura emocionalmente, ni siquiera esas lágrimas lo salvan. Al final el monstruo se queda solo. Únicamente un fervor patrio desgastado lo acompaña.

Esa suma de acciones lo llevan al territorio del exceso, de ese mundo de la condena, a las fronteras del mundo de lo aceptable. Y, mientras se hunde en su propia agonía, la carencia, ese estado patético, se arrastra definitivamente ${ }^{27}$.

\footnotetext{
27 Algunas otras resonancias se podrían encontrar en este film: el amigo encamador, los roqueros del sur, la prostituta asesina, en medio de sus peluches kicths, los cínicos banqueros, la clase alta. Todos, en algún momento, cercanos al Mal.
} 
Afuera ese exceso se representa en los banqueros, y la carencia en los huelguistas. La disputa simbólica de estos dos, terminará por sellar la suerte de Juan Castro. Así, cuando llega el momento roba un jeep y huye. Pasa cerca de sus supuestos panas y sigue de largo. Al final termina solo y enfrentado a un destino siniestro. Tal como la Tigra y Ángel. Soledades encerradas en el encuadre final, apretadas en una agonía insalvable.

Parecido es el "padre" de Salvador, el delincuente en construcción de Ratas... Hiperbólico y agresivo, estalla frente a la actitud displicente de su hijo y le propina tremenda paliza. El padre concebido como la representación de lo viejo (este y aquel de Fuera de juego, metáforas del Estado, así como de las nociones de patria, trabajo y progreso) muestran el ideal defenestrado de la paternidad. Pero de una paternidad que se entiende como dominio. La supuesta educación para la vida está concebida a partir de una exigencia retrógrada. Los jóvenes se rebelan ante esa versión de la estructura familiar.

Las madres desaparecen, ya desde la ausencia, ya desde la muerte, para que el padre asuma el conjunto del mundo. Las madres pertenecen al territorio de lo inasible. No se puede acudir a ellas. Suponen esa sociedad que las oculta, que las margina. Sólo tienen razón de ser cuando se vuelven sujetos sexuales, objetos de gozo, o deseo. En medio de esa organización simbólica dominante y masculina, Salvador no tiene cabida. De ahí que decida irse por el camino opuesto.

El "padre" recibe le visita de otro monstruo (el delincuente, el marginal feo, avezado, siniestro que a golpes desquita su furia. El padre yace en el hospital, en agonía. Así, humanizado parece dejar de lado su condición de monstruo, ese imaginario del militar retirado. Al final su muerte resulta una especie de alivio. La abuela es la única que sufre. Los párpados que caen suponen el dolor y la resignación. Aparece, así, la madre dolorosa, tan cercana a la tradición, tan atrapada en su permanencia. Y en ciclo se cierra en la condena final.

\section{Carencia y exceso}

¿Somos así en el Ecuador? ¿La Tigra, Ángel, Vinicio Cepeda, los "papitos", o ese Don Sata, o la Bestia Loca de Un titán en el ring representan parte de algo llamado ecuatorianiedad? Quizás no podamos establecer cercanías, y por ello comparaciones con otros momentos de la historia del cine. O tal vez sí. Entonces, ¿esos hombres y mujeres que huyen en las Escaleras de Odessa, represen- 
$\tan$ desde las particularidades, las épocas y los espacios similares, a aquellos que reaccionan con violencia en Crónicas? ¿Ese Dr. Caligari es parecido -desde las patologías contemporáneas-, al violador Vinicio Cepeda? ¿Desde los ojos de la Tigra podemos acercarnos a una parte del imaginario nacional, tal como en su momento hicieran los italianos con Antonio? ¿Es posible un encuentro con la idea de un Estado quebrado a partir de la documentación recreada de Fuera de Juego, así como cuando se encuentra con los valores nacionalistas en Nacimiento de una Nación? ¿En la locura de estos "papitos", o en las metáforas de la decadencia, de la inmovilidad de la abuela en Ratas... o el hermano enajenado de Fuera de Juego, es posible encontrarnos con alguna cercanía al desconcierto de la Posmodernidad, como así lo buscasen Buñuel y Dalí con su Modernidad?

No será que, de ser imposible ese reconocimiento, estemos enfrentándonos a una sentencia mayor. Tal vez nuestro cine, como nuestro país, se halla ajeno a un plan de país (en su momento las búsquedas del proyecto nacional concebido desde el Realismo Social, demuestran que cuando los afanes estéticos se juntan con los políticos es posible hablar de algo llamado identidad. La idea de "volver a tener patria” que señalada Benjamín Carrión).

No será esta una época de quiebres, de fisuras que impiden siquiera el nacimiento de una noción de lo ecuatoriano. De ahí que nuestro cine no pueda definirse, encontrarse de frente con su propio país, y tenga que travestirnos, recrearnos como monstruos, como seres de la oscuridad, atrapados y condenados a una mirada que nos cercena, que nos condena, que nos lleva hacia el territorio del exceso.

No será que nuestros cineastas conciben su ejercicio desde ciertos afanes meramente estéticos. Carentes de base política sus películas recrean la pobreza, asumen la función de retratar los personajes que habitan en sus imaginarios. La distancia entre el sujeto que mira la realidad y la realidad misma está matizada por la sensibilidad, la solidaridad y la conciencia política. Si se acude sólo con el ojo del que la recrea cabe siempre la posibilidad de distorsionar la realidad perversamente (el arte es siempre distorsión, recreación, de eso no cabe duda).

Así, la estética de la pobreza, como sus monstruos, sus paisajes decadentes resultan sólo búsquedas visuales, artilugios y mentiras. En el ejercicio de deformar a los sujetos reales se avista una necesidad prima- 
ria, narrativa, dramática en el mejor de los casos, pero leve, superficial, y vaciada de sentido ${ }^{28}$. Estos monstruos, como este cine del Ecuador, se alejan de una base histórica, se escabullen a un territorio ajeno, se configuran en un mundo ilusorio. No nos representan, no nos recuperan. Más bien nos ocultan, nos llevan a la sombra. Nos dejan, otra vez, con la sensación de la carencia, de que algo nos falta, de que ese algo podrá estar en otro lado, en otras latitudes, aun cuando esto suponga el desarraigo, el quiebre definido. Así, imposible de miraros, de salir del encierro, del laberinto, del desierto, de las aguas movedizas, del Síndrome de Ouroboros.

Siena-Lisboa, 2007.

\section{Bibliografía}
BACHELARD, Gaston
1993 La poética del espacio. Bogotá: Fondo de Cultura Econó- mica.

BAJTÍN, M.M.

1982 Estética de la creación verbal. México: Siglo Veinte Editores.

BALLO, J. y PÉREZ, Xavier

1997 La semilla inmorta: Los argumentos universales en el cine. Barcelona: Anagrama.

BATAILLE, Georges

1959 La literatura y el mal, Ser y Tiempo, Madrid: Taurus..

BOURDIEU, Pierre

1995 Las reglas del arte: Génesis y estructura del campo literario. Barcelona: Anagrama.

-_. (2000). La dominación masculina. Barcelona: Anagrama 2000.

BRAUDILLARD, Jean

1991 La transparencia del mal. Barcelona: Anagrama.

28 Nada tiene que ver, en principio, con ese tema paradigmático de otras cinematografías, en las que la monstruosidad está estrechamente vinculada con su opuesto bello, de tal suerte que la lucha del primero por alcanzar al segundo suele llevarlo a la exculpación o la salvación. La unidad "bella-bestia" permite la creación de significativas historias, cuyo motor fundamental radica en la aceptación de un "otro" a pesar de sus excesos físicos. Esa matriz de alteridad, además, puede estar cimentada en otros círculos como el poder, el cuerpo, el erotismo, cuyas interpretaciones exceden los objetivos de este ensayo. Sin embargo dejamos anotadas algunos de los films más sugestivos. Nosferatu, Cyrano de Bergerac, La bella y la bestia, El jorobado de Notre-Dame, El fantasma de la Ópera, Drácula, Eduardo Manosdetijera, King Kong. Un caso singular es Freaks de Tod Browning que, en 1932, juntó en un circo a unos cuantos seres deformes, monstruosamente reales en una historia de poética del horror feliz. Caso aparte constituye el cine de Jorodowsky, en cuya propuesta cinematográfica es posible encontrar, desde el surrealismo más delirante, toda clase de seres "deformes". 


\section{El síndrome de Ouroboros: Cine y monstruos del Ecuador}

CASTRO, Juan Pablo

2003 "Las dos tigras", en revista Kipus No. 16, Quito.

CALABRESE, Omar

1996 Cómo se lee una obra de arte. Madrid: Cátedra.

_-. (1998). La era neobarroca, Madrid: Cátedra, 1998

FORSTER, E.M.

1983 Aspectos de la novela, Madrid: Debate.
GENETTE, G.

1989 Palimpsestos. Madrid: Taurus.

MORIN, Edgar

s/f El cine o el hombre imaginario, s/r.

ZIZEK, Slaroj

2006

Lacrimal rerum: Ensayos sobre cine moderno y ciberespacio. Barcelona: Debate. 